\title{
Device for preliminary deformation of corncobs when harvesting corn for grain
}

\author{
Sergey K. Papusha ${ }^{1, *}$, Vladimir K. Papusha ${ }^{1}$, Nikolay A. Nikitenko ${ }^{1}$ \\ ${ }^{1}$ Federal State Budgetary Educational Institution of Higher Education "Kuban State Agrarian \\ University named after I.T. Trubilin”, Krasnodar, Russia
}

\begin{abstract}
The new technology involves the use of a special device for preliminary deformation of corncobs installed in the sloping chamber of a combine harvester. Installing the present device will allow to increase the service life of a harvester, to reduce grain losses and get fuel economy in the process of corn harvesting for grain by reducing stress on a concave and as a consequence, less wear. Also, when using a special device for pre-deformation of corncobs, it is possible to reduce grain crushing during threshing.
\end{abstract}

In terms of yield and feed advantages, corn surpasses all other grain crops. Corn grain is an indispensable component of feed industry, valuable raw material for food and a number of other industries. Corn plays a crucial role in creating a durable fodder base, as it produces the cheapest and most nutritious fodder in the form of green mass, silage and grain.

Harvesting is one of the most difficult and time-consuming processes of corn cultivation. Harvesting 1 hectare of ripe corn uses more labor and money than for its cultivation in 2 ... 2.5 times at present level of mechanization of cultivation.

Currently, more economical is the method of corn harvesting for grain with simultaneous threshing of cobs with combine harvesters equipped with corn harvesting attachments. However, these units have also several disadvantages: inadequacy of agricultural requirements due to increased crushing of grain under threshing; high load on the grain harvester's concave, which significantly reduces its service life [1].

Therefore, the development of new schemes of corn harvesters and highly efficient working bodies to them, as well as the improvement of existing ones is one of the important tasks.

The aim of this study is to develop a device of pre-threshing of corncobs in a sloping chamber of a corn harvester Acros -580, the use of which will reduce energy intensity of the corn threshing process in the threshing unit of a corn harvester, to reduce shock loads on the concave and to improve the quality of a corn-harvester. [2]

Purpose: to reduce grain losses, to obtain fuel saving in the process of corn harvesting for grain through the use of corn pre-threshing device in the sloping chamber of the corn harvester.

Corn for grain is removed in the form of cobs with simultaneous threshing of the latter ones.

\footnotetext{
*Corresponding author: sergey belousov 87@mail.ru
} 
The first harvesting method involves the cutting of plants, separation of cobs, chopping of stalks, cleaning of cobs from coats, drying and threshing of cobs at the station. The hexastichous self-propelled corn harvesters are used for it. The creation of specialized corn harvesters with simultaneous threshing depends on the fact that the standard grain harvesters poorly withstand shock loads during corncob threshing. The disadvantages of specialized harvesters include their high cost, narrow specialization, short period of use in the presence of a powerful engine, and, as a consequence, high operation and depreciation costs [3].

Corn harvesting of corn by harvesters with specialized attachments is more economically feasible, but the use of this method is limited by increased humidity of cobs during harvesting in a number of areas of the country.

The technological process of corn harvesting by harvesters with an attachment accompanied by frequent disruptions of the operation process is conditioned due to clogging of the threshing device, which causes deformation of the concave and reduction of the angular velocity of the drum [4]. After harvesting corn the threshing machine in the result of deformation of the concave is unable to provide further qualitative threshing of cereals. Reducing the angular velocity of the drum adversely affects the performance of the engine, which is linked with it with V-belt transmission.

Moreover, it is established that the average values of the forces at the entrance to the threshing machine are much higher than the forces at the exit, due to the fact that threshing occurs mainly in the front and middle parts of the concave.

Reduction of loads on the concave can be achieved in two ways:

- Increasing the gap between the drum and the concave;

- Supply of pre-deformed cobs into the threshing machine.

The use of the first method is limited by the fact that with increasing gaps, losses sharply are increased due to under-grinding of grain [4].

The use of the second method, as experiments had shown, is very effective. The stage of initial deformation of the cob is advisable to take out of the threshing chamber of the harvester on the corn harvesting attachment. Structurally, this can be achieved by installing an additional threshing device instead of the last beater. Previously there was offered a number of engineering solutions (A. S. USSR 1210710, A. S. 1366100 USSR). Their essence is in the fact that the cobs before entering the threshing chamber of the harvester is deformed by the crushing in the sloping chamber of the attachment by the last beater, specially equipped for this purpose [5,6].

Schemes of deformers offered in these copyright certificates are presented in Figure 1 and Figure 2.

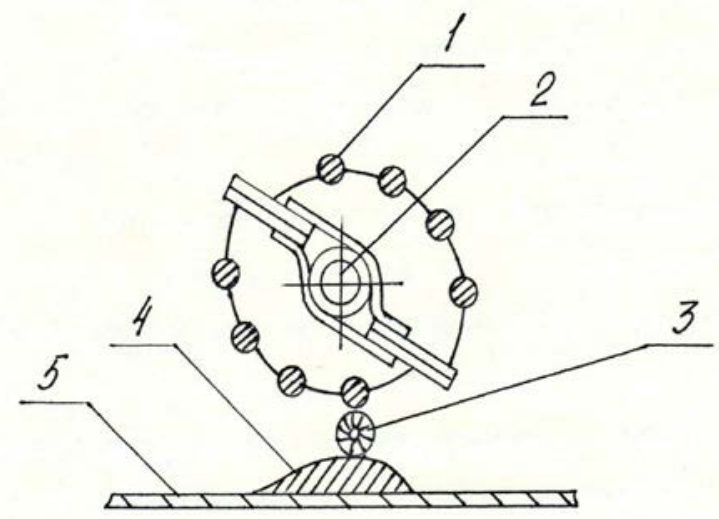

1-bars; 2-beater of sloping chamber; 3-cob; 4-vane; 5-bottom of sloping chamber.

Fig. 1. Deformer (A.S. 1210710 USSR) 


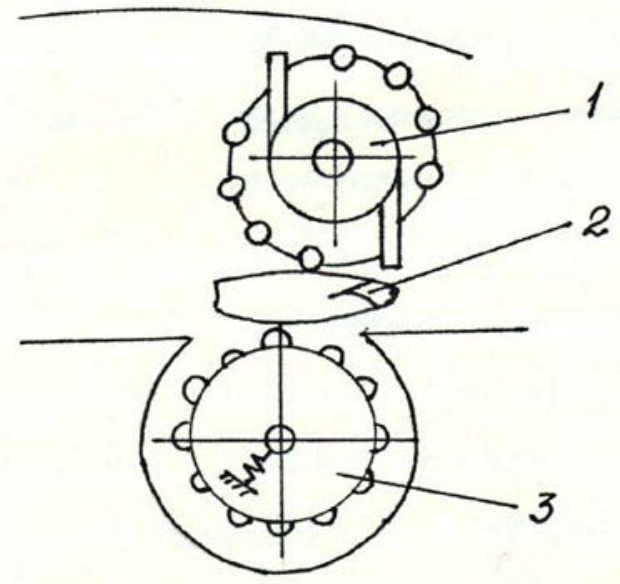

1-deformer; 2-cob; 3- rippled driving roller

Fig. 2. Deformer (A. S. 1366100 USSR)

But these solutions have not found application, because they had a number of significant drawbacks:

- A significant increase in power to the drive by increasing the friction forces of the friction forces between the beater and the cob;

- Reducing the capacity of the last beater (deformer), which led to clogging of the sloping chamber and disruption of the technological process;

- There was an increase in the percentage of damaged grain due to increased friction forces and normal forces acting on the cob;

These disadvantages can be avoided if you get rid of the friction forces between the cob and the beater, which is achieved by deformation impact [7]

To manufacture this device you need:

1) remove the slotted blades and their holding devices from the shaft of the last beater of the sloping chamber ;

2) mount the threshing blades on the shaft of the last beater;

3) mount the bottom of the pre-threshing device on the body of the sloping chamber.

The harvester with the modernized sloping chamber equipped with the device for preliminary threshing of cobs works as follows [8].

When driving along the rows the supplied chains grab the stems and enter them in the working gaps between the strapping plates and the stretching rollers of strapping cobseparating device [9]. When pulling stems by the rollers the cobs are separated from the stalks on strapping plates and by grips of supplied chains on strapping plates are discharged into the auger of cobs. Rolled stalks after separation of cobs are cut by the cutting device, crushed and scattered on the field.

Cut off cobs by the auger from all channels are moved to the sloping chamber and are moved into receiving chamber by the flat blades. The beater of the sloping chamber moves the cobs on the bottom of the camera. The penultimate beater delivers the cobs at the bottom to jump to the pre-threshing beater. By inertia, the cobs continue their movement in space, and the last modified beater hits them with the force necessary to disrupt the structure of the cob [8].

The deformed cob is supplied into the threshing device of the harvester. Threshed grain enters the cleaning system of the harvester through the deck of the threshing drum. Grain 
threshed by the pre-threshing device through a special grate instead of the flap of stone trappers immediately comes to shuttle board, bypassing the threshing apparatus of the harvester.

After cleaning (by the usual way for a grain harvester), the grain is fed into the grain hopper. Impurities, rods and coats on straw shaker enters the receiving chamber of the shredder. The crushed mass is scattered over the field.

On the basis of experimental data, the disruption of the corn structure (residual deformations) occurs when beating the cob at speed exceeding $14 \mathrm{~m} / \mathrm{s}$., the violation of the integrity of the cobs is possible at a speed of a blow about $9 \mathrm{~m} / \mathrm{s}$, which reduces energy intensity of the threshing process by $20 . . .25 \%[10,11]$. The entering into the threshing device of deformed cobs reduces the process of grain crushing.

The device for preliminary corncob threshing is a beater with two steel blades and vanes, located on the area of the last beater of the sloping chamber of the grain harvester. It also includes a specially manufactured bottom mounted on the body of the sloping chamber between the third supplying beater and the beater of the pre-threshing device.

From the above mentioned, it can be concluded that the use of devices for corncob predeformation can increase the life of the harvester, reduce grain losses and get fuel economy in the process of corn harvesting for grain [11]. Consequently, the use of corncob prethreshing device in the sloping chamber of the harvester Acros -580 will be economically feasible.

\section{References}

1. Theoretical studies of the tobacco stalk interaction with the leaf-separating unit / S.K. Papusha, S.V. Belousov, A.E. Bogus. V.I. Konovalov // International Journal of Applied Engineering Research (IJAER) Volume 11, Number 8 (2016)

2. Means of minor mechanization as a basis for modern peasant farms and small farms in small forms of management Lepshina A.I., Belousov S.V. Polytechnical network electronic scientific journal of the Kuban State Agrarian University. 2015. No. 109. P. 392-415.

3. Vinevsky E.I. Some physical and mechanical properties of plants of native tobacco varieties [Text] / E.I. Vinevsky, G.V. Gromov, A.V. Ognianik, S.K. Papusha, E.V. Shidlovsky, N.N. Vinevskaya, R.N. Bukatkin // Collected scientific works of the AllRussian Scientific Research Institute of Tobacco, Makhorka and Tobacco Products Krasnodar. - 2008. - No. 117. - p. 203-208.

4. Lugovsky V. Increase the competitiveness of poultry farming Lugovsky V. AIC: Economics, Management. 1997. No. 5. P. 81.

5. Vinevsky E.I. New technique for tobacco growing [Text] / E.I. Vinevsky, A.E. Lysenko, I.I. Dyachkin, N.N. Vinevskaya, G.V. Popov, A.I. Petriy , S.K. Papusha, K.G. Gromov, E.V. Shidlovsky, A.V. Ognianik // Achievements of science and technology of the agroindustrial complex. - 2007. - No. 6. - p. 42-45.

6. Pat. 2311013 Russian Federation, IPC A01D 45/16. Tabakouborochny combain [Text] / E.I. Vinevsky, E.V. Shidlovsky, N.N. Vinevskaya, I.B. Poyarkov, A.I. Petriy, I.I. Dyachkin, S.K. Papusha; applicant and patent holder of the GNU VNIITTI. - No. 2006106854/12; claimed. 06/03/2006; publ. 27.11.2007, Bul. № 33. - 7 with .: ill.

7. Papusha S.K. Theoretical study of the interaction of the tobacco stem with a listootdelitelnym device [Text] / S.K. Papusha, V.I. Konovalov, E.I. Vinevsky // scientific support of innovative technologies of production and storage of agricultural and food products: Collection of materials of the III All-Russian scientific-practical 
conference of young scientists and graduate students. All-Russian Research Institute of Tobacco, Makhorka and Tobacco Products. - 2016. P. 176-183.

8. Lugovsky V.A. Theoretical approaches to analysis of the problem of separation in domestic and foreign psychology Lugovsky V.A., Petrenko T.V., Sysoeva L.V. Political Internet electronic scientific journal of the Kuban State Agrarian University. 2016. No. 119. S. 539-552.

9. Belousov S.V. Application of liquid to the sphere of the combine miller Yakovenko A.V., Belousov S.V. In the collection: Scientific support for the agro-industrial complex Collection of articles based on the materials of the IX All-Russian Conference of Young Scientists. Responsible for the release: A.G. Koshchaev. 2016.S. 435-437.

10. Lugovsky V. Broilers for baby food timoshenko N., Slepukhin V., Lugovsky V., Lukashenko V., Stefanova I. Poultry farming. 2000. No. 1. S. 42-43.

11. Belousov S.V. Substantiation of the process of separation of fruits by the planetary fruit separator Ablikov V.A., Belousov S.V. In the collection: Actual problems of scientific and technological progress in the agro-industrial complex A collection of scientific articles of the XII International Scientific and Practical Conference, within the framework of the XVIII International Agricultural Exhibition "AgroUniversal - 2016". 2016.S. 3-8. 